\title{
Evaluation of Gradual Trend of Patients' Satisfaction with Complete Dentures in the Department of Prosthodontics: A Cross-sectional Study
}

Ramin Negahdari ${ }^{1}$, Seyyed Mahdi Vahid Pakdel ${ }^{2}$, Sepideh Bohluli ${ }^{3}$, Hosein Eslami ${ }^{3}$, Alireza Pournasrollah ${ }^{4 *}$

1. Assistant Professor, Department of Prosthodontics, Faculty of Dentistry, Tabriz University of Medical Science, Tabriz, Iran

2. Post-graduate student, Department of Prosthodontics, Faculty of Dentistry, Tabriz University of Medical Science, Tabriz, Iran

3. Assistant Professor, Department of Oral Medicine, Faculty of Dentistry, Tabriz University of Medical Science, Tabriz, Iran

4. Assistant Professor, Department of Prosthodontics, Faculty of Dentistry, Tabriz University of Medical Science, Tabriz, Iran

\begin{abstract}
Introduction: Despite a decrease in the number of adult edentulous individuals, the number of individuals who lose all their teeth and need complete dentures is on the increase. One of the most important principles of fabrication of complete dentures is to achieve patient satisfaction. In the present cross-sectional study, the gradual trend of patients' satisfaction with complete dentures was evaluated. Materials and methods: In a descriptive study with pre- and post-test design, carried out in 2013 on 30 patients referring to the Department of Prosthodontics, Tabriz Faulty of Dentistry, the patients' gradual satisfaction with complete dentures was evaluated one week and 2 months after delivery of dentures in 7 aspects, including masticatory efficacy, satisfaction with mastication of soft and hard foods, ease of cleaning of dentures, perception of food tastes, articulation and overall satisfaction. A researcher-made questionnaire was used, whose validity and reliability had been confirmed. The questionnaire determined the patients' satisfaction by a value ranging from zero to 10 . Repeated-measures ANOVA was used to analyze data. Results: Thirty subjects were included in the present study. Changes in patients' satisfaction from the first week to the second month were significant in terms of mastication of soft and hard food items, ease of cleaning the dentures, articulation and overall satisfaction ( $\mathrm{P}=0.022, \mathrm{P}=0.023, \mathrm{P}=0.018, \mathrm{P}=0.001$ and $\mathrm{P}=0.001$, respectively). Changes in patients' satisfaction with masticatory efficacy and perception of food tastes from the first week to the second month were not statistically significant $(P=0.092$ and $P=0.144)$. Conclusion: In the present study, patients' satisfaction increased in all the aspects. Although such increase in satisfaction with mastication of soft and hard foods, ease of cleaning the dentures, articulation and overall satisfaction was statistically significant, it was not significant in relation to perception of food tastes and masticatory efficacy.
\end{abstract}

Key words: Complete dentures; patient satisfaction; cross-sectional;

\section{Corresponding author:}

Alireza Pournasrollah

Assistant Professor, Department of Prosthodontics, Faculty of Dentistry, Tabriz University of Medical Science, Tabriz, Iran

Email: pournasrollah@razi.tums.ac.ir

Receive date: 2016-02-06 | Accept date: 2016-03-29| Publish date: 2016-04-19

DOI: 10.7575/aiac.abcmed.16.04.02.04 


\section{Introduction}

During the past 30 years, the prevalence of edentulism has decreased in developed countries (1). In this context, the edentulous population decreased from $30 \%$ in 1978 to $21 \%$ in 1989 in the United Kingdom. A study in the United States showed that $41 \%$ of the population over 65 years of age were edentulous in 1985 and 1986 (2). However, despite the decrease in the number of adult individuals with edentulism in European and North American countries, given the increase in population, especially in developing countries, in general the number of edentulous individuals requiring complete dentures is on the increase in these countries (3). Given the ever-increasing number of individuals wearing complete dentures, patients' satisfaction with complete dentures is of utmost importance, making it necessary for the dentists to increase their knowledge about the principles of fabrication and maintenance of complete dentures. It is incumbent on dentists to apply correct diagnostic and therapeutic techniques during the fabrication of removable complete dentures (3). They should take into account the physiologic, anatomic and psychological status of each patient along with the medical health status of each patient. Subsequent to correct diagnosis and proper treatment planning, the dentist should make sure of the accuracy of laboratory procedures, too (4).

Despite such considerations, dentists still encounter patients who are not able to properly use their dentures and have problems with them despite the fact that all the considerations have been taken into account. After the patient receives his/her complete dentures, a wide range of problems are encountered (5-18).

Considering the high prevalence of edentulism in our country and the high prevalence of administration of complete dentures, the present cross-sectional study was undertaken to evaluate the gradual trend of patients' satisfaction with their complete dentures.

\section{Materials and Methods}

A total of 30 edentulous patients referring to the Department of Prosthodontics, Tabriz Faculty of Dentistry, were included in this descriptive cross-sectional study with a preand post-test design. The subjects were all candidates for fabrication of complete dentures and referred to the above-mentioned center during the first half of 2012. The subjects were collected randomly and included in the study. The inclusion criteria consisted of subjects with high school education and higher so that they were able to complete the questionnaire and score the variables under study; an age range of 20-60 years, and absence of resorption of the edentulous ridge, with at least $15 \mathrm{~mm}$ of edentulous ridge height in the mandible. The exclusion criteria consisted of affliction with systemic conditions or psychological diseases and a history of wearing complete or partial dentures. In order to eliminate the effect of biomechanics variable on patients, an attempt was made in the present study to evaluate the gradual trend of satisfaction and the patients were compared with themselves over a period of time. The questionnaire consisted of questions on patients' demographic data and patients' satisfaction with dentures in relation to comfort during mastication of foods, mastication of soft and hard food items, ease of cleaning the oral cavity and the dentures, perception of different food tastes, ease of speaking and the overall satisfaction. Each question was scored from zero to 10 , with zero indicating the least degree of satisfaction and 10 indicating the highest degree of satisfaction.

After completing the questionnaire and collection of data, the patients' satisfaction levels were compared 1 week and 2 months after treatment with complete dentures. 


\section{Results}

The mean scores of food mastication one week and two months after the delivery of complete dentures were $5.3 \pm 0.83$ and $5.63 \pm 0.66$ out of 10 , respectively, with no significant differences ( $P=0.092)$ (Graph $A)$. The mean scores of comfort during mastication of soft food items one week and two months after delivery were $5.63 \pm 0.66$ and $6.26 \pm 0.78$ out of 10 , respectively, with statistically significant differences $(P=0.22)$. In other words, the patients' comfort during mastication of soft food items had significantly improved after two months compared to that after one week (Graph B). The mean scores of comfort during mastication of hard food items one week and two months after delivery were $5 \pm 1.01$ and $5.6 \pm 0.96$ out of 10 , respectively, with statistically significant differences $(P=0.023)$ (Graph C). The mean scores of ease of cleaning the dentures one week and two months after delivery were $4.53 \pm 1$ and $4.96 \pm 0.92$ out of 10 , respectively, with statistically significant differences ( $P=0.018$ ) (Graph $D)$. The mean scores of perception of different tastes one week and two months after delivery were $5.48 \pm 1.15$ and $5.89 \pm 0.90$ out of 10 , respectively, with no statistically significant differences $(P=0.144)$ (Graph E). The mean scores of patients' satisfaction with articulation one week and two months after delivery were $4.2 \pm 1.12$ and $5.96 \pm 0.88$ out of 10 , respectively, with statistically significant differences $(P=0.001)$ (Graph F). The mean scores of patients' overall satisfaction one week and two months after delivery were $4.96 \pm 0.85$ and $5.66 \pm 0.75$ out of 10 , respectively, with statistically significant differences $(P=0.0012)$ (Graph G).

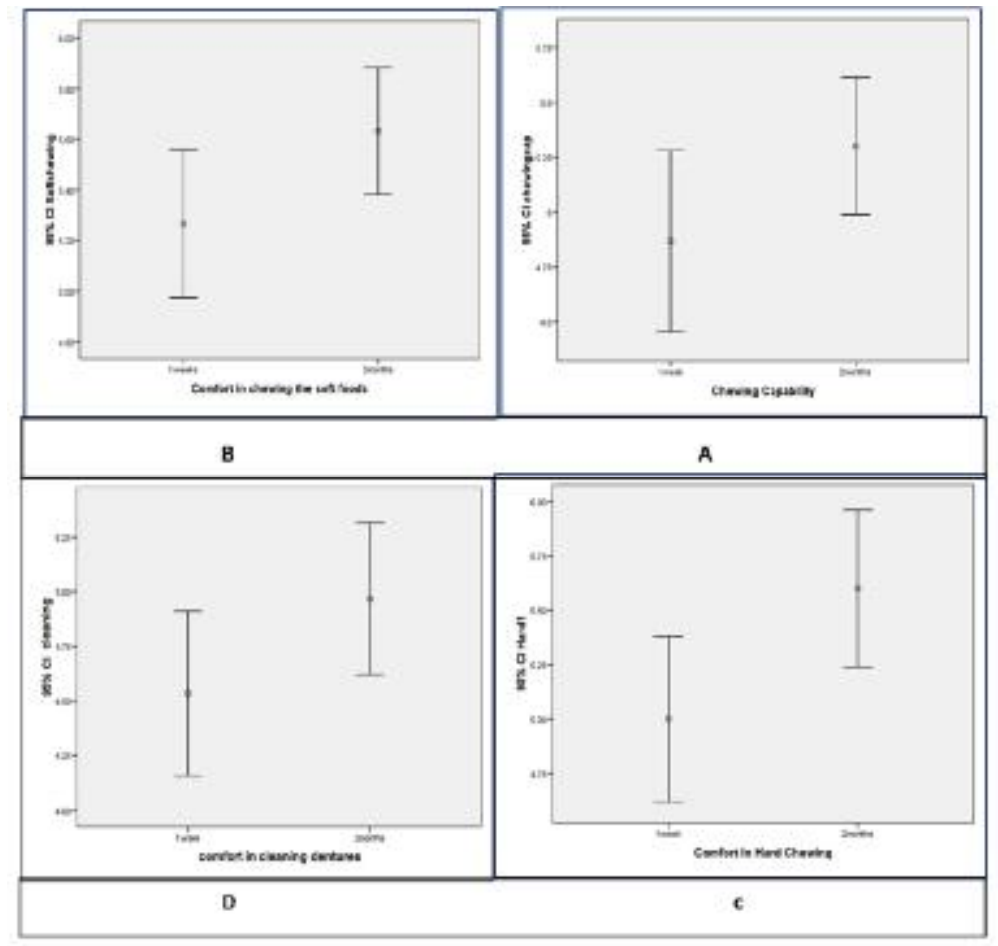

Figure 1: The graphs of the variables under study: A. Masticatory efficacy; B. Comfort during mastication of soft food items; C. Comfort during mastication of hard food items; D. Ease of cleaning the dentures 


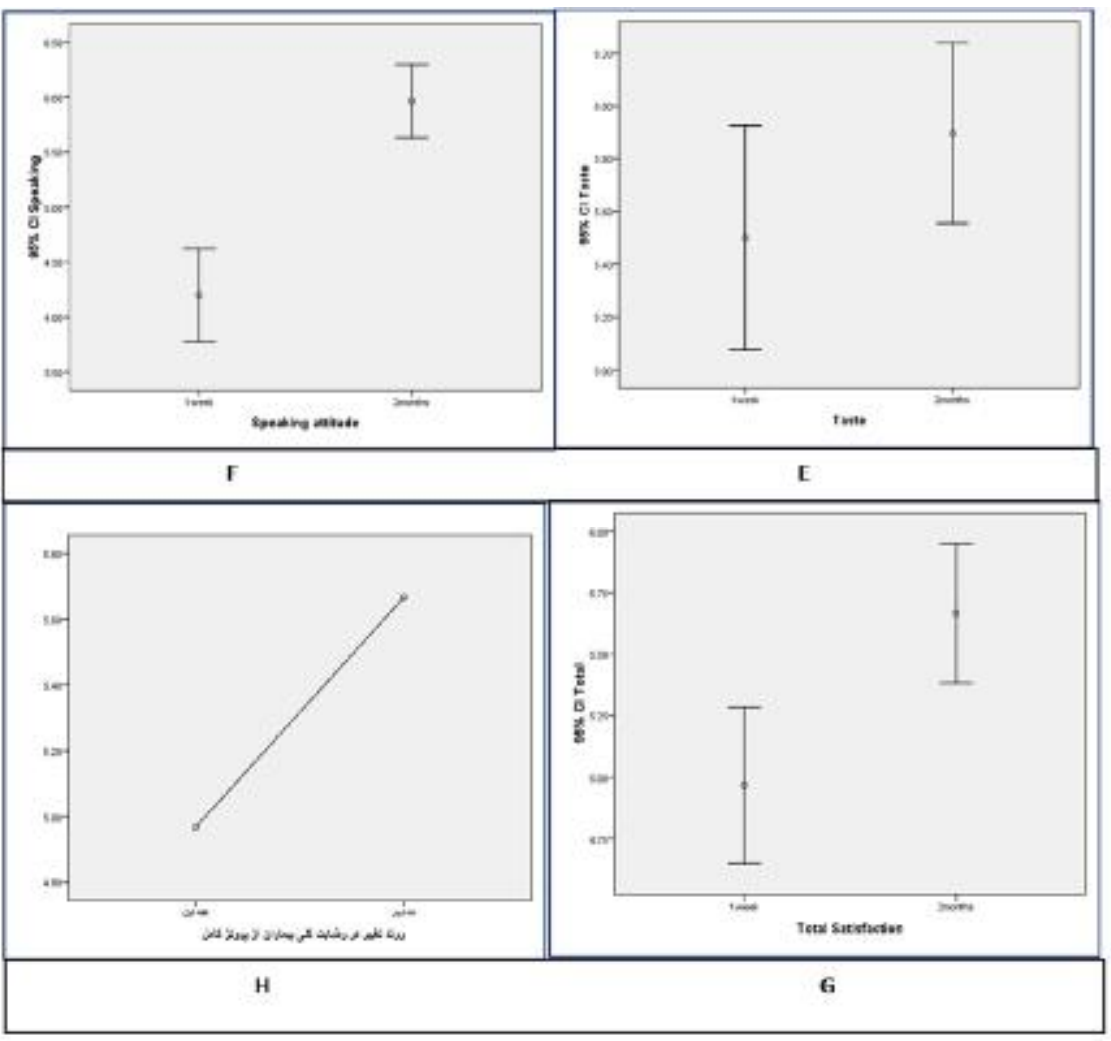

Figure 2: The graphs of the variables under study: E. Perception of different tastes; F. Satisfaction with articulation; G. Patients' overall satisfaction one week and two months after delivery; $\mathrm{H}$. Comparison of patients' overall satisfaction after one week and two months

\section{Discussion}

As discussed above, the individuals wearing fixed and removable dentures comprise a major proportion of dental patients, making it important to pay attention to the problems of these patients. The present study evaluated the gradual trend of patients' satisfaction with complete dentures. Based on analyses carried out, the patients' satisfaction level increased in all the areas evaluated. However, such increase in satisfaction in relation to mastication of soft and hard food items, ease of cleaning of dentures, articulation and overall satisfaction was statistically significant but the increase in satisfaction in relation to perception of different tastes and masticatory efficacy was not statistically significant.
In addition, the subjects expressed the highest satisfaction, during the first week of denture wearing, with perception of food tastes and the lowest with ease of articulation. These results are consistent with those of similar studies.

In a study by Alsharafat et al, the patients generally became satisfied with the complete dentures manufactured for them and the highest satisfaction was expressed in relation to the denture shape, ease of use, ease of speaking, perception of food tastes and ease of cleaning of dentures. A small number of patients complained of pain during function of their dentures and in general recommended this treatment to patients with the same problem (20). 
In the present study, too, the highest satisfaction at the beginning of denture wearing was expressed with the mastication of soft food items, followed by perception of food tastes. Furthermore, the highest dissatisfaction was expressed with articulation, consistent with the results reported by Alshrafat. In addition, in the present study, the patients were generally satisfied with their dentures, which is also consistent with the results of the study mentioned above.

Mastication and articulation with ease is possible with dentures when the dentures have adequate retention and do not cause pain during function. Nonspecific pain which is mainly due to pressure on the zygomatic process or due to the extension of the distobuccal border of the maxillary denture is diagnosed by palpating the zygomatic area and evaluation of any separation of the denture during excursions of the mandible (23).

Pain in the posterior palate is due to a deep posterior dam, resulting in pain in the palate and fauces and dysphagia. Pain in the area posterior to the maxillary prosthesis during opening of the mouth is due to a thick distobuccal flange and interference with the coronoid process (20).

Biting of the buccal mucosa is another problem that occurs due to various reasons, including incorrect reconstruction of the functional width of the sulcus, insufficient transverse overlap (under $2 \mathrm{~mm}$, which can be solved by making the buccal cusps of the lower denture round), a distance of less than 3-4 mm between the bases of the upper and lower dentures, and sharp buccal cusps, which can be corrected by making them round. Biting of the lip is due to the inadequate support of the lip or inadequate transverse overlapping of the anterior region $(20,22,24)$.

In the present study, the highest satisfaction was expressed with mastication of soft food items one week after the delivery of dentures. In a study by Zlatric et al, the majority of problems with dentures were related to mastication, articulation and the denture shape (21). Consistent with the study just mentioned, the most important and prevalent problem of patients at the beginning of denture wearing was articulation. These findings are consistent with those of the present study, in which the highest satisfaction was expressed with mastication of soft food items and the lowest with articulation.

A variable which was evaluated in the present study almost for the first time was the gradual trend of patients' satisfaction, which was evaluated one week and two months after the delivery of dentures. As mentioned above, in almost all the fields the patients' satisfaction increased significantly, which shows the role of adaptation in patients' evaluation of the dentures fabricated for them.

Furthermore, the highest dissatisfaction immediately after delivery was related to the ability to speak. It is possible that the inability to speak and difficulty in articulation might be due to ill-fitting dentures. The majority of patient complaints are related to mandibular dentures because there is less supporting surface area in the mandibular denture compared to the maxillary denture. However, such a problem might occur with the upper or lower dentures immediately after wearing the denture, during wide mouth opening, during speech, during mastication or at any other time (19).

Inadequate extension of the labial and buccal flanges of mandibular denture, which is diagnosed with the protrusive movement of the lip and buccal mucosa and observation of a space between the border and the mucobuccal fold or the buccal mucosa, too, is one of the factors responsible for a decrease in retention (19). This shows the importance of attention to 
correct impression taking during the initial evaluation of patients.

On the other hand, some problems are due to the psychological problems of the patients, including intolerance, mental problems and depression, which result in discomfort, denture mobility and functional problems. In such cases, the patient should express his/her feelings freely in order to help physicians solve the problem to some extent by dedicating sufficient time to such problems.

\section{Conclusion}

With ever-increasing use of complete dentures, attention should be focused on their problems and attempts should be made to solve the problems of denture wearers. Based on the analyses carried out in the present study, patients' satisfaction increased in all the aspects evaluated; such increase in satisfaction in relation to the mastication of soft and hard foods, ease of cleaning the dentures, articulation and the overall satisfaction was statistically significant, but it was not significant in relation to perception of food tastes and masticatory efficacy. In addition, the highest satisfaction after one week of delivery of dentures was related to the perception of food tastes and the lowest was related to ease of articulation.

\section{References}

1. Douglass CW, Shih A, Ostry L.(2002). Will there be a need for complete dentures in the United States in 2020. J Prosthet Dent, 87(1), 5-8.

2. Anderson GF, Hussey PS.(2000). Population aging: A comparison among industrialized countries. Health Affairs, 19(3), 191-203.

3. Winkler S.(1997). Symposium on complete denture. Dent Clin North Am, 21(2), 197-8.

4. McCord JF, Grant AA, Quayle AA.(1992). Treatment options for the edentulous mandible. Eur J Prosthodont Rest Dent, 1(1), 19-23.

5. McCord JF, Grant A.(2000).A clinical assessment. Br Dent J, 188(7), 375-80.

6. Kennedy CA.(1982). Troubleshooting in full denture construction. J Prosthet Dent, 3(5), 660.

7. Landa JS.(1999). Troubleshooting in complete denture prosthesis: Part 1, Oral mucosa and border extention. J Prosthet Dent, 9(6), 978.

8. Landa JS.(1999). Troubleshooting in complete denture prosthesis: Part 2, Lesions of the oral mucosa and their correction. J Prosthet Dent, 10(1), 42.

9. Landa JS.(1999). Troubleshooting in complete denture prosthesis: Part 3, Traumatic injuries. J Prosthet Dent, 10(2), 263.

10. Landa JS.(1960).Troubleshooting in complete denture prosthesis: Part 5, Local and systemic involvements. J Prosthet Dent, 10(4), 682.

11. Landa JS.(1960) Troubleshooting in complete denture prosthesis: Part 6, Factors of oral hygiene, chemicotoxicity, nutrition, allergy and conductivity. J Prosthet Dent, 10(5), 887.

12. Landa JS.(1960). Troubleshooting in complete denture prosthesis: Part 7, Mucosal irritations. J Prosthet Dent, 10(6), 1022.

13. Landa JS.(1961). Troubleshooting in complete denture prosthesis: Part 8, Interferences with anatomic structures. J Prosthet Dent, 11(1), 79.

14. Rothman R.(1961). Phonetic considerations in denture construction. J Prosthet Dent, 11(2), 214.

15. Krol AJ.(1999). A new approach to the gagging problem. J Prosthet Dent, 13(4), 611. 
16. Tourne LP, Luc PM, Fricton JR.(1992). Burning mouth syndrome. Oral Surg Oral Med Oral Pathol, 74(2), $158-67$.

17. Morstad AT, Peterson AD.(2006). Post insertion denture problems. J Prosthet Dent; 19(2), 126.

18. Lutes MR.(1972). Denture modification during adjustment phase of complete denture service. J Prosthet Dent, 28(6), 572.

19. McCord JF, Grant AA.(2000).Identification of complete denture problems: A summary. Br Dent J, 189(3), 128-34.

20. AL.Sharafat F.(2000). Assessment of the Relation between patients attitude and patients satisfaction with complete dentures. Pakistan Oral \& Dental Journal, 2(3), 12-16.

21. Zlataric D,Zore I, Jerolimov V, Celic R, Celebic A, Peruzovic M. et al.(2000).Patients' Satisfaction with Partial Denture Therapy. Acta Stomat Croat, 34(4), 373-8.

22. Awad MA, Feine JS.(1998).Measuring patient satisfaction with mandibular prostheses. Community Dent Oral Epidemiol, 26(6), 400-5.

23. Diehl RL, Foerster U, Sposetti VJ, Dolan TA.(1996). Factors associated with successful denture therapy. J Prosthodont ,5(2), 84-90.

24. Smith PW, McCord JF.(2004). What do patients expect from complete dentures. J Dent, 32(1), 3-7. 